\title{
Construcción del concepto de Currículum en los contextos educativos
}

\section{Construction of the concept of Curriculum in educational contexts}

HERNÁNDEZ-CUETO, Jaquelina Lizet†*, SALINAS-AGUIRRE, María del Consuelo, YAÑEZFLORES, Sara Margarita y ARRIAGA-REYES, Rosa Argelia

Universidad Autónoma de Coahuila

ID $1^{\mathrm{er}}$ Autor: Jaquelina Lizet, Hernández-Cueto / ORC ID: 0000-0002- 3728- 7434, Researcher ID Thomson: S-85882018, CVU CONACYT ID: 322702

ID $1^{\mathrm{er}}$ Coautor: María Del Consuelo, Salinas-Aguirre / ORC ID: 0000-0002-6542-1813, Researcher ID Thomson: S-92442018, CVU CONACYT ID: 615635

ID $2^{\text {do }}$ Coautor: Sara Margarita, Yañez-Flores / ORC ID: 0000-0002-4750-4244, Researcher ID Thomson: S-9231-2018, CVU CONACYT ID: 352125

ID $3^{\text {er }}$ Coautor: Rosa Argelia, Arriaga-Reyes / ORC ID: 0000-0001-7130-9206, CVU CONACYT ID: 1067612

DOI: $10.35429 / J E S C .2020 .4 .12 .1 .5$

Recibido: 04 de Octubre, 2020; Aceptado 22 de Noviembre, 2020

\section{Resumen}

El presente artículo dilucida el concepto de currículum, de forma entitativa a los procesos educativos. Consiste en una investigación documental que trata de dar cuenta de la construcción del currículum tanto de forma cronológica en principio y en la perspectiva educativa en una segunda instancia. Se hace un recorrido panorámico por los principales autores internacionales y énfasis en los autores nacionales, ya que se cuenta con un gran desarrollo en este campo disciplinar por parte de investigadores mexicanos. La importancia de este trabajo radica principalmente en que anteriormente se circunscribía el término currículum únicamente al plan de estudios o malla curricular, sin embargo cuenta con un sinnúmero de elementos que dan direccionalidad al proceso educativo en cuanto a los actores, la metodología, la infraestructura, los contenidos programáticos, etc.

\section{Currículum}

\begin{abstract}
This article elucidates the concept of curriculum, in an entitative way to educational processes. It consists of a documentary investigation that tries to account for the construction of the curriculum both chronologically in principle and from the educational perspective in a second instance. A panoramic tour is made of the main international authors and a small emphasis on national authors, since there is a great development in this disciplinary field by Mexican researchers. The importance of this work lies mainly in the former confining the term curriculum only to the curriculum or curriculum mesh, however it has countless elements that give directionality to the educational process in terms of actors, methodology, infrastructure, programmatic contents, etc.
\end{abstract}

Curriculum

Citación: HERNÁNDEZ-CUETO, Jaquelina Lizet, SALINAS-AGUIRRE, María del Consuelo, YAÑEZ-FLORES, Sara Margarita y ARRIAGA-REYES, Rosa Argelia. Construcción del concepto de Currículum en los contextos educativos. Revista Ciencias de la Educación. 2020. 4-12: 1-5

\footnotetext{
* Correspondencia del Autor (Correo electrónico: jaquelina.hernandez.cueto@uadec.edu.mx)

$\dagger$ Investigador contribuyendo como primer autor.
} 


\section{Introducción}

La presente investgación documental pretende tratar de dilucidar un concepto integrado de varios autores y perspectivas, ya que hasta la fecha no puede hablarse de un concepto universalmente convergente. Dentro de los contextos educativos nacionales e internacionales es palpable que se han incorporado cambios a la forma en que funcionan los diseños curriculares $\mathrm{o}$ a la conformación de los mismos. Existen un sinnúmero de situaciones no resultas en el diseño de ambientes tendientes a que se produzca el aprendizaje.

El currículum y de forma más específica el diseño curricular, da la oportunidad de seleccionar los insumos pertinentes y que vayan acordes con nuevas tendencias como el caso de la neurodidáctica en cuanto a prácticas áulicas y de forma general al diseño del perfil del estudiante por ejemplo de forma virtual para situaciones de emergencia como es el de la contingencia mundial por casos de salud.

\section{Desarrollo teórico del concepto currículum}

En un principio, para integrar al currículum en una perspectiva del contexto social y educativo de su reconstrucción, es necesario delimitar el concepto de currículum per se. Incluso hay que precisar en la especificidad de su nomenclatura, ya que en la literatura comúnmente se suele utilizar de manera indiscriminada las palabras currícula, curricula, currículas, currículum, curriculum, curricular y similares, para referirse al mismo concepto; sin embargo, como lo menciona Gómez (1994), "Nuestro idioma conserva palabras en su forma latina en expresiones como "per cápita" (acentuado en castellano), "de facto", ad unguem, ad litteram, in specie, ad nauseam, etc. Sin embargo, lo más común es que las palabras latinas se castellanicen." (p. 2)

Lo que implica que aunque se adopten palabras latinas en escritura igual a cómo son de origen, en el idioma español se castellanizan, esto es que tienen que adscribirse a las reglas ortográficas del idioma. Por tal razón en particular la palabra curriculum al ser esdrújula debe ir acentuada.

También Gómez (1994), precisa que:
La forma "la currícula" en castellano, es un barbarismo: el artículo "la" es femenino singular, y currícula (palabra latina de uso inglés) es neutro plural. Se trata en todo caso de una mala traducción del inglés. Un buen traductor debe dominar los idiomas: el original que está leyendo y del que está traduciendo y el idioma "destinatario" en el que escribe lo traducido. Este barbarismo de "la curricula" y, lo que es peor, de "las currículas" es uno de los muchos que se han ido imponiendo en nuestro castellano de México por la tremenda invasión cultural del inglés y por el desconocimiento de ambos idiomas: del inglés y del español. Más aún: se trata de una triple ignorancia: del inglés, del castellano y... del latín. (p. 3)

Es muy importante destacar dicho problema de nomenclatura para comprender la forma en que los autores manejan los términos y su conocimiento sobre el tema. Una concepción reduccionista del concepto de currículum, la da Goodson (1995), ya que lo refiere como contenidos programáticos insertos en un programa. Ahí maneja la dicotomía de lo que debe contener un currículo cuando atiende a la orientación disciplinar y lo que implica cuando se hace desde una perspectiva sociológica. Para el caso del primero, estará envuelto en la naturaleza del conocimiento para conocer cuál es el más valioso. En la segunda perspectiva, es para que una vez que se adquiere el aprendizaje puedan las personas emanciparse socialmente. Dicha bifurcación la enfrenta también la escuela como institución, cuando sus alumnos son socializados en el marco de una cultura en particular; y cuando son preparados para su inserción en el mundo laboral.

Arnaz (2010), describe el curriculum (sin acento) como:

[...] un plan que norma y conduce explícitamente, un proceso concreto $y$ determinado de enseñanza-aprendizaje que se desarrolla en una institución educativa. [...] es un conjunto interrelacionado de conceptos, proposiciones y normas estructurado de forma anticipada a acciones que se quiere organizar; en otras palabras, es una construcción conceptual destinada a conducir acciones, pero no es las acciones mismas, si bien de ellas se desprenden evidencias que hacen posible introducir ajustes o modificaciones al plan. (pp. 9-10) 
En esta perspectiva comienza a plantearse la interrogante de si el diseño curricular es real o esperado. Si los conceptos concatenan en acciones de forma determinante o si existen otras condiciones para concretarlas.

Otro concepto lo ofrece Zabalza (2007), indicando en principio que no hay una delimitación única, sino que cada autor ha ido aportando al tema. En síntesis indica que el currículum es:

[...] el proyecto que determina los objetivos de la educación escolar, es decir, los aspectos del desarrollo y de la incorporación a la cultura que la escuela trata de promover y propone en un plan de acción adecuado para la consecución de esos objetivos.

Se entiende que el currículum escolar concreta todo el conjunto de oportunidades de desarrollo personal y de adquisición de nuevos aprendizajes que la escuela ofrece a los sujetos en edad escolar. En él se especifica el compromiso del Estado con respecto a la educación, expresado tanto en términos de intenciones -exigencias (lo que los sujetos escolarizados han de aprender) como de recursos puestos a su disposición para lograrlo (profesorado, instituciones, organización de la escolaridad, recursos materiales, etc.) (p. III)

En esta delimitación se apertura a los elementos particulares de la educación escolarizada; por lo que se presume que el ambiente de aprendizaje a que refiere es institucional y formal. Incluye además, la tendencia del currículum al desarrollo personal y humano.

Por su parte Díaz (2012), da un recorrido cronológico e incluye en su descripción a autores como Bobbit, Charter, Tyler y Taba entre otros. De esta última, incluye la noción de diagnóstico de necesidades, para darle al currículum una perspectiva más objetiva al incluir a la investigación como actividad necesaria para el diseño de planes y programas.

Esta perspectiva es importante en cuanto a que los diseños curriculares deberán responder a una necesidad explícita y tangible; no así a una direccionalidad expuesta por autoridades o tomadores de decisiones.
Díaz (1993), da varias delimitaciones del currículum, la primera como estructura organizada de conocimientos; la segunda como sistema tecnológico de producción; la tercera como plan de instrucción; la cuarta como un conjunto de experiencias de aprendizaje y finalmente la quinta como la reconstrucción del conocimiento y propuesta de acción. Dando más peso a esta última, en marcada oposición a las anteriores.

La implicación del currículum en los contextos social y educativo radica en que este tendrá la responsabilidad de ofrecer una educación según el nivel educativo en su caso una profesión que dé respuesta a las necesidades no solamente del sujeto que estudia, sino de la sociedad.

Dar un sentido social al currículum hace que lo que se aprenda en los salones de clase no sirva únicamente para incrementar el conocimiento sobre un tema determinado; sino que a partir de lo que se aprenda las personas logren solucionar problemáticas e insertarse en un mundo laboral cada vez más competitivo de forma exitosa.

Actualmente no basta únicamente con terminar una carrera, es necesario que tenga oferta de trabajo y que el producto de dicho proceso sea una pieza clave en el desarrollo social. La educación debe servir a las personas para ser y vivir mejor.

La perspectiva social está implícita en los principios del humanismo, que se ha vuelto a poner de moda y no porque no se hablara de él, sino porque se estaba tan preocupado porque los estudiantes aprendieran la malla curricular y tuvieran muchos contenidos, que de alguna manera la parte de la interacción y el beneficio al colectivo se vio menguada.

\section{Construcción de una definición personal de currículum}

Con base en los autores revisados conceptualizamos al currículum como la estructura más importante en los procesos educativos. Ya que visiona a priori todo cuanto compete a una institución académica en el sentido de que demarca las características que deberán tener los egresados, plasmado en un perfil. 
Define la misión y visión de la institución; especifica el tipo de figura educativa que puede llevar a cabo los procesos didácticomatéticos; delimita los contenidos programáticos que logren consolidar los objetivos del programa; considera la infraestructura de edificación en donde habrá de erigirse la escuela; incide en estudios de pertinencia y factibilidad, así como de seguimiento a los egresados. Es decir, engloba todo lo que de forma previa se necesita para iniciar un proceso educativo.

Es proceso, pero también se consolida en producto, ya que tipifica en el caso del nivel superior una preparación para un campo disciplinar y pragmático particular, que diferencie a otro profesionista. Prevé la adquisición de habilidades y en su caso de competencias. Además de sistematizar y equilibrar lo que las personas aprenden en créditos para las asignaturas; anteriormente con el sistema Tepic y actualmente con el SATCA.

Consideramos que los sistemas educativos actualmente están permitiendo no solamente como un constructo coloquial, sino como una perspectiva objetiva la inclusión de elementos que permitan a los estudiantes el desarrollo de la inteligencia emocional, y es que debería hacer parte de los diseños curriculares de cualquier nivel, ya que aparentemente a nadie le importa que el estudiante sea feliz en esta etapa. $\mathrm{Y}$ con los estudios hechos a la postre sobre este tópico) se sabe ya, que una persona con estabilidad emocional y ambiente de aprendizaje positivo, logra obtener más insumos que una que adolece de esa parte.

Una vez delimitado el concepto de currículum y su implicación en los enfoques sociales y educativos; hay que hablar sobre los aspectos que debe cubrir en estos tópicos.

Díaz (1993), refiere a la aportación de Hilda Taba enunciando que ella "[...] introduce al campo del diseño curricular una noción sumamente importante: la del diagnóstico de necesidades sociales, como sustento principal de una propuesta curricular. Establece explícitamente el vínculo escuela-sociedad que está detrás de un proyecto curricular." (p. 32)
Sin embargo, también discute si el currículum debe circunscribirse únicamente a la necesidad de la sociedad reduciendo los planes y programas a demandas inmediatas, específicas y utilitaristas que puedan ir en detrimento de la formación del sujeto. Es decir si se da gusto a la necesidad de la sociedad, por ejemplo en un sitio donde haya fábricas automotrices de procedencia coreana; y la universidad decida incluir en su malla aprendizaje del coreano en una ingeniería industrial. Le va a servir para un fin inmediato, pero no garantiza el éxito ni la vigencia del aprendizaje, porque puede ser que ese mismo año implementen una fábrica de procedencia alemana.

De forma muy precisa Escorcia, Gutiérrez \& Henríquez (2005), indican que la educación superior tiene una gran responsabilidad puesto que debe atender a los desafíos que permitan el impulso de la competitividad y la globalización de la actividad humana; para ello y en pro de atender a las tendencias mundiales, indican que en este nivel debe considerarse lo siguiente:

- $\quad$ Actualización permanente del currículo.

- Articulación entre los procesos formativos y las demandas de la sociedad contemporánea.

- Atención, desde la universidad, a los retos de la sociedad contemporánea, como una estrategia que le permita ser pertinente y mantenerse como institución social que contribuye con el desarrollo.

- Valoración y exaltación de la diversidad material y humana.

- Análisis de los múltiples escenarios de desempeño laboral.

- Valoración, exaltación y aceleración del cambio.

- $\quad$ Exaltación de la sostenibilidad ambiental como valor universal.

- Reconocimiento de la dimensión humana en los individuos.

- Definición de los contenidos, desempeños y aptitudes esenciales en la formación de los sujetos, en el marco de una sociedad cada vez más cambiante, exigente, globalizada y competitiva. ( $\mathrm{p}$. 64)

Con lo que puede observarse que el proceso educativo daría solución y atención no solamente a la perspectiva individual, sino al papel de los sujetos en colectivos. 


\section{Conclusión}

Finalmente tras una revisión lacónica de teoría entitativa al currículum, en pro de la construcción de un concepto se puede concluir que el currículum o de forma más particular el diseño curricular juega un papel determinante en el rumbo que toman los sistemas educativos del mundo. Definen lo que las personas van a saber para desenvolverse en la vida y en el campo laboral. Dan la formata del hombre al especificar qué conocimientos, habilidades e incluso valores va adquirir en un proceso educativo institucional.

Por tanto, como reflexión, queda que las personas encargadas tanto de las reformas educativas como del diseño o rediseño de currícula, independientemente del nivel educativo al que se encuentren adscritos, debe poseer no solamente conocimiento sobre su campo disciplinar, sino también de lo que es un currículum. Ya que no debe quedar fuera de la perspectiva las formas de trabajo áulico, los actores de la educación o la implicación del contexto en la conformación de lo que a priori se ha determinado será producto de un proceso educativo.

\section{Referencias}

Arnaz, J. (2010). La planeación curricular. México. Editorial Trillas.

Gómez, J. (1994). ¿Currícula o currículas? Revista Sinéctica 4. ISSN: 1665-109X. Disponible en: https://sinectica.iteso.mx/index.php/SINECTIC A/article/view/547

Díaz, A. (2012). Didáctica y currículum. México. Editorial Paidós Educador.

Díaz, F. (1993). Aproximaciones metodológicas al diseño curricular: hacia una propuesta integral. Revista Tecnología y Comunicación Educativa. Disponible en: http://tyce.ilce.edu.mx/tyce/21/TecyComEduNo 21_A02.pdf

Escorcia, R., Gutiérrez, A. \& Henríquez, H. (2005). La reestructuración curricular como resultado de los procesos sociales. Revista ieRed: Revista Electrónica de la Red de Investigación Educativa. ISSN 1794-8061 Disponible en: http://revista.iered.org
Zabalza, M. (2007). Diseño y desarrollo curricular. España. Editorial narcea. 